function in failing hearts. These findings have sparked a number of experimental and clinical studies aimed at restoring intracellular $\mathrm{Ca}^{2+}$ homoeostasis using viral gene transfer of $\mathrm{Ca}^{2+}$ transporter to the human myocardium; however, significant abnormalities in $\mathrm{Ca}^{2+}$ handling characterise late-stage heart failure and may not be the initiating factor. To test this hypothesis, we compared LV myocytes from C57BL6 mice 12 weeks after coronary ligation (causing an infarct $>35 \%$ by $3 \mathrm{D}$ echocardiography) or sham surgery. LV ejection fraction was significantly reduced in infarcted mice versus shams ( $23 \%$ vs $55 \%$, $\mathrm{p}<0.0001, \mathrm{n}=9$ in each group) and the heart weight or lung weight to body weight ratios were significantly increased. LV myocytes isolated from infarcted hearts were significantly larger than those from sham operated hearts $(p=0.001)$. The distribution of cell shortening and cell size measured in 'unselected' LV myocytes (ie, from all the live cells in a given field) was much wider in infarcted mice than in sham-operated controls. However, basal cell shortening $(3 \mathrm{~Hz}$, field stimulation at $35^{\circ} \mathrm{C}$ ) was enhanced in myocytes from infarcted hearts $(p=0.001)$, as was the amplitude of the $\left[\mathrm{Ca}^{2+}\right]_{i}$ transient $(p<0.0001)$ and the SR Ca content $(10 \mathrm{mM}$ caffeine spritz, $\mathrm{p}=0.04)$. The rate of decay of $\left[\mathrm{Ca}^{2+}\right]_{\mathrm{i}}$ was faster both in field-stimulated $(p<0.0001)$ and caffeine-induced $\left[\mathrm{Ca}^{2+}\right]_{\mathrm{i}}$ transients, suggesting upregulation of the $\mathrm{Na}^{+} / \mathrm{Ca}^{2+}$ exchanger activity. The myocyte inotropic response to increasing doses of isoproterenol or stimulation frequency $(0.5-3 \mathrm{~Hz})$ was similar, despite significant LV dysfunction and reduced $\beta$-adrenergic reserve in vivo. In summary, impaired LV performance post-myocardial infarction can occur in the absence of obvious $\mathrm{Ca}^{2+}$ and contraction abnormalities at the single myocyte level. These findings suggest that relatively minor changes in myocardial architecture, in terms of the distribution of cell properties, may lead to significant LV dysfunction and to the syndrome of heart failure well before individual myocytes show a significant deficit in contractility.

\section{PLASMA LEVELS OF THE NOVEL VASODILATORY GAS HYDROGEN SULPHIDE ARE ASSOCIATED WITH ADIPOSITY}

doi:10.1136/hrt.2009.191064n

M Whiteman, K M Gooding, J L Whatmore, K Skinner, C Ball, J E Tooke, A C Shore. Peninsula Medical School, St Luke's Ts Campus, Magdalen Road, Exeter, Devon, UK; Peninsula National Institute of Health Research Clinical Research Facility, Exeter, UK

Background Vascular synthesis of the novel endogenous vasodilatory and redox active gas hydrogen sulfide $\left(\mathrm{H}_{2} \mathrm{~S}\right)$ is perturbed in animal models of hypertension and diabetes. ${ }^{1}$ However, the role of H2S in the human vasculature in health or disease is unknown. We have investigated whether plasma H2S levels correlated to physical, clinical and biochemical indices of obesity and diabetes in men.

Methods Plasma was obtained from male patients with type 2 diabetes mellitus (T2DM; $n=11$ ), overweight (OW; $n=16)$ and lean $(\mathrm{n}=11)$ healthy male volunteers, and $\mathrm{H}_{2} \mathrm{~S}$ levels were determined by zinc-trap spectrophotometry. Anthropometric measurements (body mass index, waist-hip ratio), lipid profile, systemic blood pressure and indices of diabetes (fasting glucose, insulin sensitivity, glycated haemoglobin) were determined.

Results Mean plasma $\mathrm{H}_{2} \mathrm{~S}$ levels were significantly lower in T2DM patients (mean \pm SD $12.73 \pm 8.67 \mu \mathrm{M}$ ) compared with lean
(41.1 $\pm 17.9 \mu \mathrm{M}, \mathrm{p}=0.001$ Mann-Whitney $\mathrm{U}$ test) and OW (OW $22.93 \pm 7.96 \mu \mathrm{M}, \mathrm{p}=0.008)$ volunteers. Mean plasma $\mathrm{H}_{2} \mathrm{~S}$ levels in OW volunteers were significantly lower than in lean controls $(p=0.003)$. Waist-hip ratio was a significant independent predictor of plasma $\mathrm{H}_{2} \mathrm{~S}(\mathrm{R} 2=0.431, \mathrm{p}<0.001$; standardised $\beta-0.657, \mathrm{p}<0.001$ linear regression) in the whole group. This relationship was independent of diabetes status, which contributed $4 \%$ to the model $(\mathrm{R} 2=0.472)$. Waist-hip ratio remained an independent predictor of plasma $\mathrm{H}_{2} \mathrm{~S}$ when adjusted for systolic blood pressure, insulin sensitivity, glycaemic control and lipid profile. These findings were reflected with both body mass index and waist circumference.

Conclusions The reduction in plasma $\mathrm{H}_{2} \mathrm{~S}$ in both OW and T2DM male individuals is primarily driven by adiposity.

\section{REFERENCE}

1. Whiteman M, Moore. J Cell Mot Med 2009;13:488-507.

\section{PROTECTIVE ROLE OF PEROXISOME PROLIFERATOR-ACTIVATED RECEPTOR Ia/ $/ \mathrm{a}^{\prime}$ IN CARDIAC DYSFUNCTION AND ORGAN INJURY/INFLAMMATION CAUSED BY ENDOTOXIN IN MICE}

doi:10.1136/hrt.2009.1910640

A Kapoor, Y Shintani, M Collino, L K Bailey, N S A Patel, B Sepodes, P Tripatara, S Castiglia, R Fantozzi, H Mota-Filipe, K Suzuki, J A Mitchell, C Thiemermann. Centre for Translational Medicine and Therapeutics, William Harvey Research Institute, UK

Peroxisome proliferator-activated receptor (PPAR)- $\mathrm{I}^{\mathrm{a} 2} / \mathrm{I}^{\mathrm{a}^{\prime}}$ is a transcription factor that belongs to the PPAR nuclear hormone receptor family. There is little information about the ligands of PPAR- $\mathrm{I}^{\mathrm{a}} / \mathrm{I}^{\mathrm{a}}$ and the effect of specific activation (eg, GW0742) of PPAR- $\mathrm{I}^{2} / \mathrm{I}^{\mathrm{a}^{\prime}}$ in animal models of shock. Here we used PPAR-I $\mathrm{I}^{2} / \mathrm{I}^{\mathrm{a}^{\prime}}$ knockout (ko) mice to investigate the role of this transcription factor in a lipopolysaccharide-induced model of cardiac dysfunction and organ injury/ inflammation. When challenged with lipopolysaccharide $(9 \mathrm{mg} / \mathrm{kg}$ intraperitoneally) for $16 \mathrm{~h}$, ko mice exhibited a significant reduction in cardiac function when compared with wild-type (wt) mice, as revealed by echocardiography. When compared with wt mice, ko mice exhibited significantly increased serum levels of creatinine (renal dysfunction) and alanine aminotransferase (hepatocellular injury). In C57/BL6 mice, administration of the highly selective PPAR-I ${ }^{2} / \mathrm{I}^{\mathrm{a}^{\prime}}$ agonist GW0742 $(0.03 \mathrm{mg} / \mathrm{kg}$ intravenously $) 1 \mathrm{~h}$ after lipopolysaccharide challenge significantly attenuated the cardiac dysfunction caused by lipopolysaccharide-induced endotoxaemia, as revealed by echocardiography and the isolated-perfused Langendorff heart. Pre-treatment with a highly selective PPAR- $\mathrm{I}^{\mathrm{a}} / \mathrm{I}^{\mathrm{a}^{\prime}}$ antagonist GSK0660 $(0.1 \mathrm{mg} / \mathrm{kg}$ intravenously) 30 minutes before lipopolysaccharide reduced the cardioprotective effect of GW0742. When compared with mice challenged with lipopolysaccharide alone, GW0742 significantly attenuated creatinine serum levels and lung myeloperoxidase activity (lung inflammation). Our results suggest potential physiological ligands of PPAR- $\mathrm{I}^{2} / \mathrm{I}^{\mathrm{a}^{\prime}}$, which can afford a protective role in lipopolysaccharide-induced cardiac dysfunction and organ injury, as indicated by the loss of the receptor. Subsequently, activation of the receptor with a specific agonist, GW0742, inhibits the cardiac dysfunction and organ injury/inflammation caused by lipopolysaccharide-induced endotoxemia. 